\title{
Efficiency of Biomass Use for Blast Furnace Injection
}

\author{
Alexander $\mathrm{BABICH},{ }^{1) *}$ Dieter SENK, ${ }^{1)}$ Jon SOLAR $^{2)}$ and Isabel de MARCO ${ }^{2)}$ \\ 1) Department of Ferrous Metallurgy (IEHK), RWTH Aachen University, Intzestrasse 1, 52072 Aachen, Germany. \\ 2) School of Engineering of Bilbao (UPV/EHU), Bilbao, 48013 Spain.
}

(Received on May 30, 2019; accepted on June 24, 2019)

\begin{abstract}
Numerous studies and available experience proved the feasibility and benefits of the biomass usage in various metallurgical applications, particularly, by its injection into the blast furnace (BF). This contribution focuses on three aspects, which could increase the economic efficiency of this technology.

The first one is related to the thermal treatment of biomass. Woody biomass were pyrolysed using a laboratory pyrolysis plant under different conditions resulting in various amounts and properties of solid, liquid and gaseous constituents. Co-injection of the produced charcoal and biogas into the BF was proposed. Mathematical modelling using the experimental data of mentioned biomass product characteristics was undertaken to examine the effect of this technology on the BF operation results.

The second aspect is related to the optimisation of grain size and size distribution of injected solid biomass products. Tests using a laboratory injection rig allowed for recommendation of the coarser grinding of charcoal than that for fossil coal applied for the BF injection. This could lead to the additional energy and cost saving.

The third aspect concerns the improvement of the BF control. It is proposed a new BASE ${ }^{1}$ method for the BF thermal state control by adaption of the pyrolysis parameters while injecting pyrolysed biomass and coupling the blast furnace with a pyrolysis reactor.
\end{abstract}

KEY WORDS: ironmaking; charcoal; biogas; pyrolysis and gasification; co-injection; BF control.

\section{Introduction}

Use of biomass as a renewable energy source is one of few possibilities to mitigate the $\mathrm{CO}_{2}$ emissions in the steel industry in short and middle terms. There are three main options for their application: ${ }^{1,2)}$

- injection into shaft furnaces or electric arc furnaces

- incorporation into the burden materials or into the coal blend for cokemaking

- generation of a reducing gas.

The biggest $\mathrm{CO}_{2}$ mitigation potential exhibits the $\mathrm{BF}$ charcoal powder injection, Table 1.,3-5)

Chemical, physical and mechanical properties of raw biomass do not enable their efficient use in the steel industry, with exception for the reducing gas production by gasification. The thermal treatment by pyrolysis improves the required quality characteristics of biomass. ${ }^{1)}$ It should be stressed that, on the one side, pyrolysis promotes higher carbon content, calorific value, apparent density, lower oxygen content, better grindability etc., but, on the other side, causes the lower solid product yield (CC or TB).

Charcoal conversion behaviour under the $\mathrm{BF}$ raceway simulating conditions is comparable or even better than that for pulverised coal (PC). Particularly at high injection rate, charcoal conversion behaviour becomes more favourable because the deficit of oxygen in the blast might be com-

\footnotetext{
* Corresponding author: E-mail: babich@iehk.rwth-aachen.de DOI: https://doi.org/10.2355/isijinternational.ISIJINT-2019-337
}

pensated partly by oxygen in charcoal macropores, which act as normal holes in an atomic grid. ${ }^{1,2)}$ The oxygen in the organic functional groups in cell walls does not contribute for combustion. Concerning the torrefied materials, the performed experiments showed that only materials produced at the temperature of somewhat higher than $300^{\circ} \mathrm{C}$ might be suitable for injection into the BF. ${ }^{2)}$ A further study proved that unburnt under the raceway simulating conditions charcoal particles, can be consumed outside the raceway e.g. by solution loss reaction. ${ }^{6,7)}$

$\mathrm{BF}$ operation results depend on the injected biomass product chemistry and BF parameters. Thus, according to the modelling results, injection of charcoal with low ash and high basicity instead of PC, decreases slag volume and coke rate, and increases the furnace productivity; top gas volume and its calorific value decrease as well. When injecting charcoal with high ash content and relatively low basicity, main operation parameters including coke rate and productivity can worsen depending on the reference PC characteristics. ${ }^{1,6)}$ Injection of high amount of torrefied biomass characterised by high volatile matter, low carbon content and low calorific value, would worsen strongly the BF operation; therefore, by the calculations reported in Ref., 1 ) only $50 \%$ of PC was replaced with TB. The coke replacement ratio for charcoal could be close or even more than 1 ; for torrefied biomass its value does not exceed $0.4 .^{1,8,9)}$ 
Table 1. Biomass potential for $\mathrm{CO}_{2}$ mitigation by its applications in different ironmaking technologies.

\begin{tabular}{ccccc}
\hline $\begin{array}{c}\text { Application and replace } \\
\text { carbon source }\end{array}$ & $\begin{array}{c}\text { Typical rate } \\
(\mathrm{kg} / \mathrm{tHM})\end{array}$ & $\mathrm{BM}^{1}$ substitution rate & $\begin{array}{c}\text { Potential BM amount } \\
(\mathrm{kg} / \mathrm{tHM})\end{array}$ & $\begin{array}{c}\mathrm{CO}_{2} \text { emission } \\
\text { net reduction }\end{array}$ \\
\hline Coke making & $280-360$ & $2-5 \%$ & $5.6-18$ & $0.5-2 \%$ \\
BF lump charcoal charge & $280-360$ & $2-10 \%$ & $5.6-36$ & $1-5 \%$ \\
BF PC tuyere injection & $180-220$ & $100 \%\left(\mathrm{as} \mathrm{CC}^{2}\right)$ & $180-220$ & $20-25 \%$ \\
BF PC tuyere injection & $180-220$ & $50 \%\left(\mathrm{as} \mathrm{TB}^{3}\right)$ & $90-110$ & $10-12 \%$ \\
BF nut coke & $30-60$ & $50-100 \%$ & $15-60$ & $2-8 \%$ \\
Sintering solid fuel & $45-60$ & $25 \%$ & $11-15$ & $2.5-4 \%$ \\
$\mathrm{SRP}^{4} /$ composites & $50-100$ & $6-18 \%(\mathrm{adding})$ & $3-18$ & to be estimated \\
Gasification & & $\uparrow\left(\mathrm{CO}+\mathrm{H}_{2}\right) /\left(\mathrm{CO}_{2}+\mathrm{H}_{2} \mathrm{O}\right)^{5}$ & & to be estimated \\
\hline
\end{tabular}

${ }^{1}$ max rate of biomass solid product according to currently available results

${ }^{2}$ charcoal

${ }^{3}$ torrefied biomass

${ }^{4}$ self-reducing pellets

${ }^{5}$ the ratio should be as high as possible

These results make clear that the winnings in the biomass solid product yield causes the loss in the BF operation efficiency and vice versa. Therefore, in this work, the co-injection of charcoals and gaseous pyrolysis products targeting at the raising the total economic efficiency has been proposed and examined. The co-injection of solid, gaseous and liquid auxiliary reducing agents via separate lances is known in the $\mathrm{BF}$ practice. Thus, injection of $\mathrm{PC}$ and natural gas, heavy oil and natural gas, waste plastics and oil, $\mathrm{PC}$ and hot reducing gas, and further combinations of auxiliary reducing agents have been applied. ${ }^{10-12)}$

Another possibility to increase the efficiency of biomass product injection is an optimisation of charcoal grain size. Fine grinding intensifies the conversion of solid injectants due to rising the particle specific surface, but increases costs for the grinding due to additional electrical energy consumption, reduces mill productivity and may also worsen pneumatic transport, since the smallest particles have the tendency to stick together. The typically used grain size of $\mathrm{PC}$ should not be a reference for charcoals due to their different properties and microstructure.

Usage of injected biomass products for the BF control might be a further way for rising their efficiency. A method for controlling the BF thermal state while injecting $\mathrm{PC}$ is known. ${ }^{11)}$ It is based on timely intoned actions from the BF top and bottom by changing the coke and $\mathrm{PC}$ rates. The main benefit is caused by the fact that control actions "from the bottom" are virtually free of transport delay. While injecting biomass products, additionally to the absence of transport delay, flexible adjustment of the pyrolysis parameters can be used for precise and efficient control of the BF thermal state.

\section{Production of Biomass Constituents by Pyrolysis and Gasification}

Discussed above charcoal and terrified biomass are solid products of the biomass pyrolysis and torrefaction respectively. Pyrolysis can be defined as thermal decomposition in an oxygen-free or oxygen-poor atmosphere $(\lambda \approx 0)$ at temperatures above some $300^{\circ} \mathrm{C}^{13)}$ There is low temperature $\left(<500^{\circ} \mathrm{C}\right)$, mid temperature $\left(500-800^{\circ} \mathrm{C}\right)$ and high temperature $\left(>800^{\circ} \mathrm{C}\right)$ pyrolysis. The torrefaction process is a mild pyrolysis with maximum temperatures typically below $300^{\circ} \mathrm{C}$. Beside of solid products, also liquid and gaseous products are generated by pyrolysis of biomass. Their share depends primarily on the type of pyrolysis process. It is distinguished between flash, fast and slow pyrolysis. ${ }^{14)}$ Rapid heating rates and moderate operation temperatures (fast pyrolysis) produce maximum liquid yields, resulting in a lower proportion of solids and gas. On the contrary, slow heating processes (slow pyrolysis) result in higher solid yields and lower liquid yields, enhancing gas generation. ${ }^{15}$ )

In this study, the pyrolysis experiments were carried out using a laboratory scale continuous pyrolysis plant at the School of Engineering of Bilbao (UPV/EHU), Spain (Fig. 1). The pyrolysis reactor is an externally heated tubular screw reactor (auger reactor), where both temperature and rotation speed of the screws can be set individually. Two consecutive screws are installed in order to control the biomass flow, the first screw controls the sample feeding rate while the second screw pushes the sample through the reactor and controls the residence time inside the pyrolysis reactor. The external electrical heating is split into four individual heating zones where the temperature is adjusted separately. The produced charcoal is collected into a hopper and the vapours are further thermally treated in the tubular vapour reactor to promote further cracking, with the aim of diminishing tars and improving the composition of the gas phase. The produced vapours are then separated into biooils and pyrolysis gases, the gases are finally cleaned and analysed by online gas chromatography.

Wooden biomass (pine) from forest thinning activities were pyrolysed under different conditions. Samples of 500 $\mathrm{g}$ with size range of 50-2 $000 \mu \mathrm{m}$, main fraction $<1.0$ $\mathrm{mm}$ were used. Amount und composition of solid, liquid and gaseous products of pyrolysis of a certain biomass type is determined by the pyrolysis parameters, primarily by temperature profiles, heating rates and residence time. With rising pyrolysis temperature, solid yield decreases, gas yield increases while liquid yield increases at temperatures $300-500^{\circ} \mathrm{C}$ and decrease over $500^{\circ} \mathrm{C}$. Increase of residence time increases gas yields and decreases solid and liquid yields. The higher the pyrolysis temperature, the greater the $\mathrm{CO}$ and $\mathrm{H}_{2}$ contents and the lower the $\mathrm{CO}_{2}$ and $\mathrm{CH}_{4}$ con- 


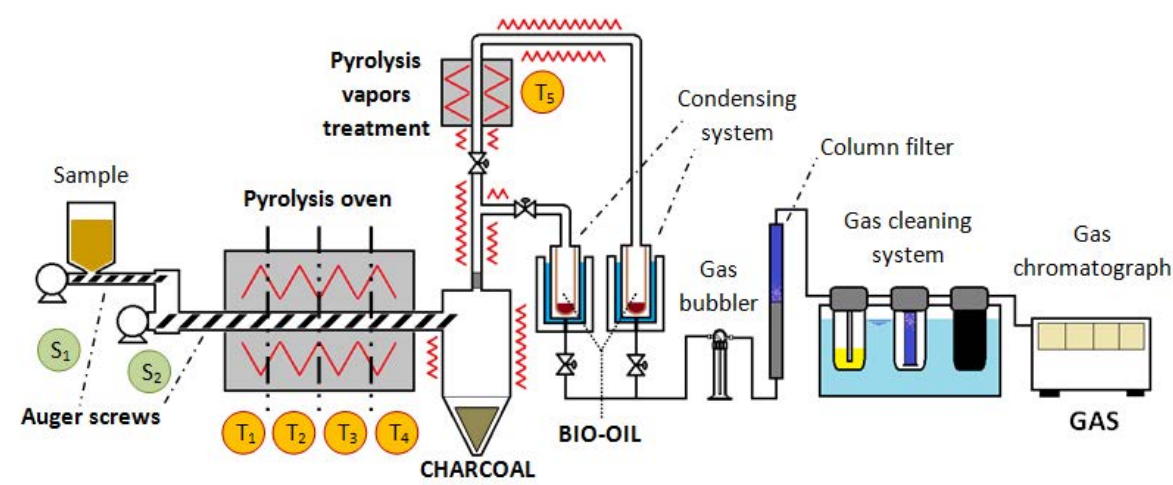

(a)

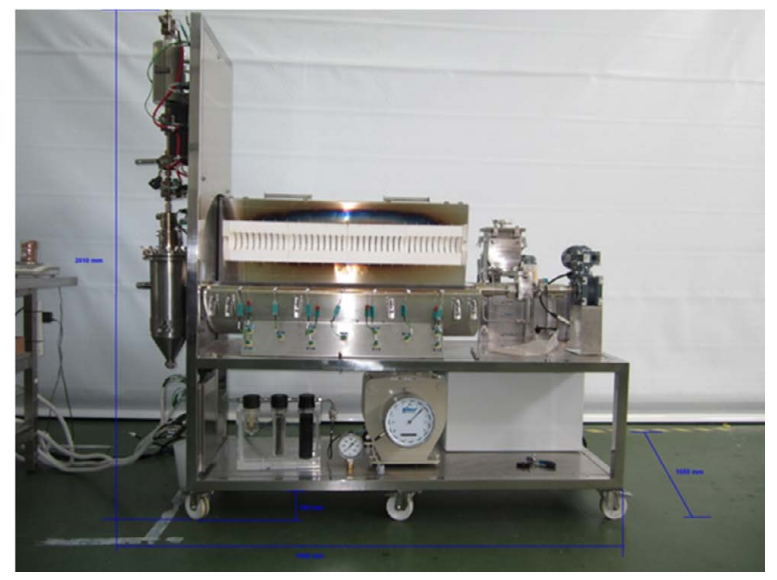

(b)

Fig. 1. Pyrolysis plant, schematic drawing and actual picture. ${ }^{16)}$ (Online version in color.)

tents of the pyrolysis gases. In the performed experiments, the yield of pyrolysis products could be varied in the range of 20-54 wt.\% solids, 6-40 wt.\% liquids and 10-75 wt.\% gases. Main components of biogas were in the range, vol. $\%$ : $\mathrm{H}_{2}=8-50, \mathrm{CO}=20-47, \mathrm{CH}_{4}=5-18$ depending on the residence time (about 30 and $60 \mathrm{~min}$ ) and various iso- and non-isothermal temperature profiles in four heating zones $\mathrm{T}_{1}-\mathrm{T}_{4}$ in Fig. 1 (from 300 to $900^{\circ} \mathrm{C}$ ), and, partly, on the catalyst used. ${ }^{16)}$ Table 2 shows examples of compositions of woody biomass (raw BM) and charcoal (CC), along with a reference $\mathrm{PC}$ used for the $\mathrm{BF}$ injection.

Table 3 shows two examples of biogas compositions produced at the pine pyrolysis ("raw BM" in Table 1) at peak temperatures of $900^{\circ} \mathrm{C}$ and different residence time. Due to high ratio of reducing components (nearly 80 vol.\% of hydrogen, carbon monoxide and hydrocarbons), such a pyrolysis gas can be used as a synthetic reduction agent, e.g. for $\mathrm{BF}$ injection.

Biogas not accompanying with charcoal can also be generated by biomass gasification, e.g. in a fluidised bed. In this study, the pilot HTW plant (High-Temperature-Winkler gasifier) at IEHK, RWTH Aachen, Germany was used, which is a gasification reactor in a circulated fluidised bed (CFB) with a diameter of $230 \mathrm{~mm}$ and a height of approx. 4 meters, Figs. 2 and 3. ${ }^{2,18,19)}$ The raw gas flows thought a recirculation cyclone to bring back the bigger particles. A second cyclone cleans the raw gas. The gasifier has three nozzle levels, two at the bottom to create the fluidised bed,
Table 2. Chemical analysis of raw biomass (BM), charcoal (CC) and PC, wt.\%.

\begin{tabular}{lrrc}
\hline & Raw BM & \multicolumn{1}{c}{ CC } & \multicolumn{1}{c}{ PC } \\
\hline Ultimate analysis: & & & \\
Carbon & 57.7 & 88.26 & 80.6 \\
Hydrogen & 7.2 & 2.71 & 4.35 \\
Oxygen & 34.8 & 8.42 & 5.35 \\
Nitrogen & 0.3 & 0.21 & 1.65 \\
$\quad$ Sulphur & trace & 0.03 & 0.45 \\
Proximate analysis: & & & \\
moisture & 10.8 & 2.3 & 1.2 \\
$\quad$ volatile matter & 64.4 & 6.0 & 17.2 \\
ash content & 1.2 & 0.6 & 10.89 \\
Ash composition: & & & \\
CaO & 35.6 & 35.6 & 1.49 \\
$\quad \mathrm{SiO}_{2}$ & 9.5 & 9.5 & 57.15 \\
\hline
\end{tabular}

Table 3. Examples of pyrolysis biogas composition, vol.\%, after 17).

\begin{tabular}{ccccccc}
\hline $\mathrm{H}_{2}$ & $\mathrm{CO}$ & $\mathrm{CO}_{2}$ & $\mathrm{CH}_{4}$ & $\mathrm{C}_{2} \mathrm{H}_{6}$ & $\mathrm{C}_{2} \mathrm{H}_{4}$ & Abbr. \\
\hline 47.52 & 35.05 & 8.63 & 8.54 & 0.05 & 0.21 & PG1 \\
41.24 & 27.77 & 9.14 & 17.13 & 2.42 & 2,30 & PG2 \\
\hline
\end{tabular}




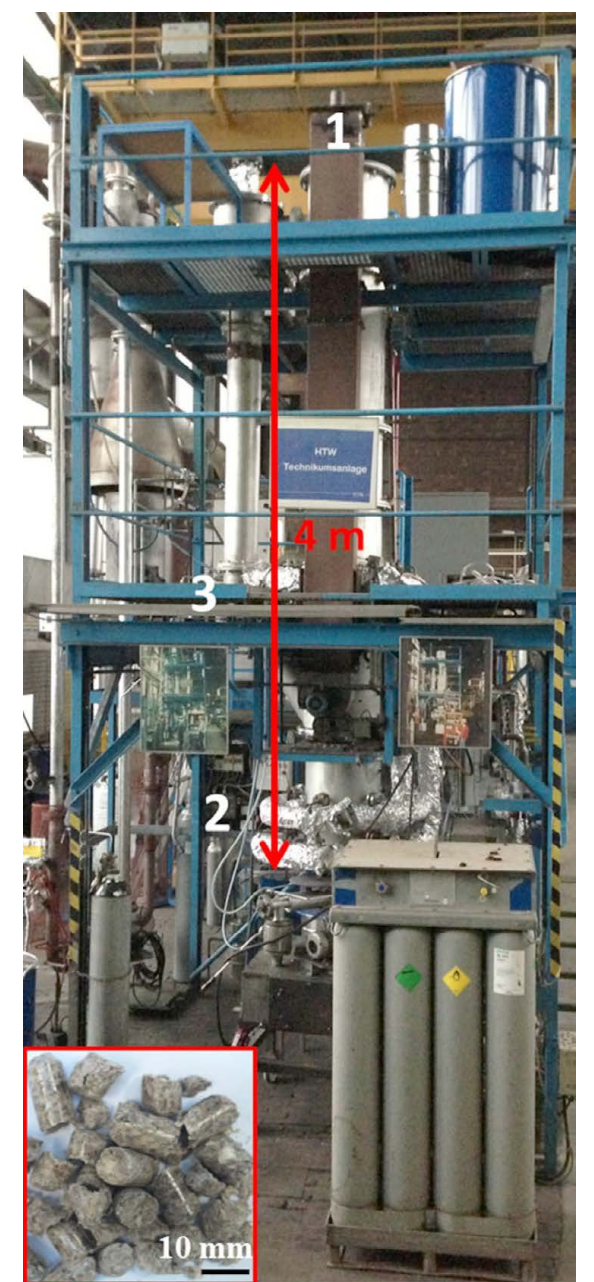

Fig. 2. The HTW gasifyer at IEHK and woody pellets used for the syngas production: 1: silo for materials, 2 : $\mathrm{CFB}, 3$ : free board. (Online version in color.)

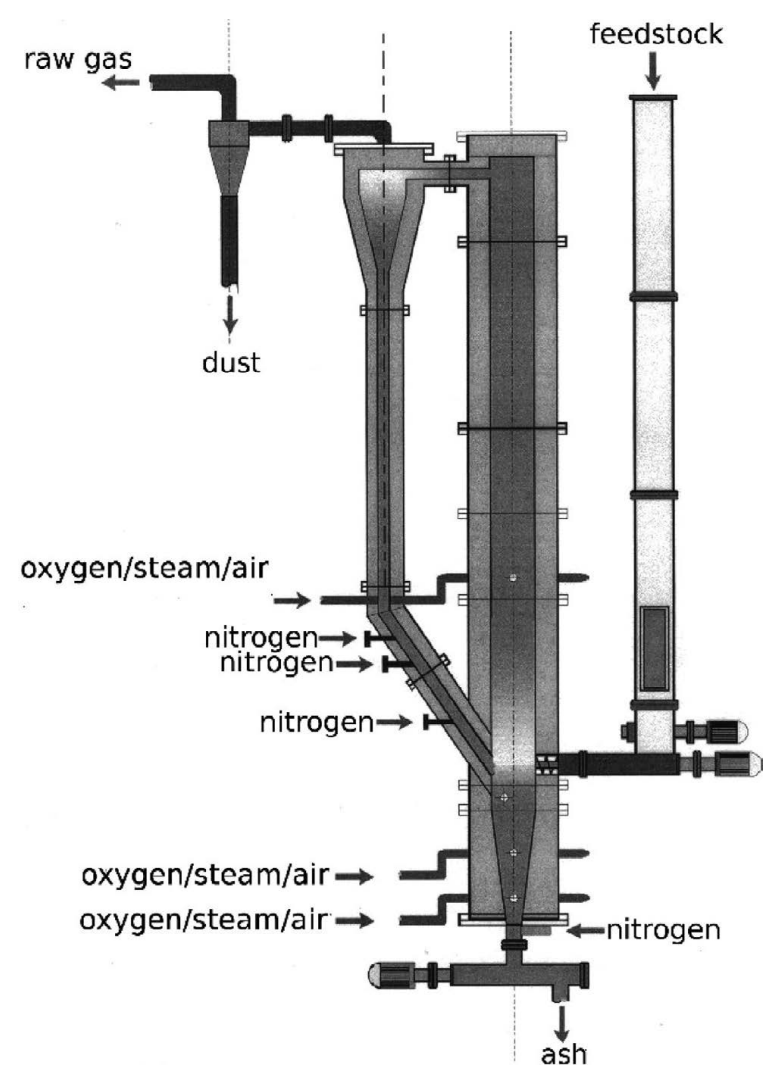

Fig. 3. Schematic draw of the HTW.
Table 4. Example of synthetic biogas composition, vol. $\%{ }^{18)}$

\begin{tabular}{ccccccc}
\hline $\mathrm{H}_{2}$ & $\mathrm{CO}$ & $\mathrm{H}_{2} \mathrm{O}$ & $\mathrm{CO}_{2}$ & $\mathrm{CH}_{4}$ & $\mathrm{~N}_{2}$ & Abbr. \\
\hline 35.68 & 37.09 & 3.95 & 9.74 & 0.01 & 13.53 & SG \\
\hline
\end{tabular}

Table 5. Ultimate analysis and ash content of raw biomass, wt.\%. ${ }^{18)}$

\begin{tabular}{cccc}
\hline $\mathrm{C}$ & $\mathrm{H}$ & $\mathrm{N}$ & $\mathrm{O}$ \\
\hline 52,05 & 6,27 & 0,26 & 41,42 \\
\hline
\end{tabular}

and one at the top for post combustion. Air, oxygen and steam can be used as fluidising gases. These gases can also be used in the post combustion zone.

Table 4 shows an example of biogas produced in this plant from woody pellets made from loblolly pine (Table 5).

\section{CO-injection of Charcoal and Biogas}

Combined injection of solid and gaseous biomass products, such as charcoal and biogas may increase the total efficiency of biomass usage in the blast furnace. To evaluate the effect of co-injection of charcoal and biogas on the BF operating results, calculations using the mathematical model introduced in Ref. 10) were conducted. This mathematical model is based on the interrelations of material and heat balance equations. The key calculations determine:

1) amount of oxygen released during reduction

2) injected substance characteristics: total amount of C, $\mathrm{H}, \mathrm{O}$ and $\mathrm{N}$, heat released by burning in the raceway etc.

3) volume of bosh gas

4) direct/indirect reduction rate

5) coke and total reducing agent consumption and blast volume

6) flux consumption and slag volume

7) top gas parameter (volume, temperature, composition, calorific value)

8) heat balance (heat generated and absorbed)

9) flame temperature

10) change in the productivity and intensity of the coke combustion.

This model was applied in various studies while injecting charcoals and torrefied biomass. ${ }^{1,6)}$ To make possible comparative analysis with mentioned studies, the same burden and blast conditions for the reference (or base) case were chosen. Amount and composition of iron burden, slag basicity and coke quality are given in Refs. 6, 20). Replacement of PC with charcoal (column 2 vs. column 1 in Table 6) was discussed in mentioned references. Here the focus is put on the additionally injected biogases.

Table 6 shows relevant blast characteristics and selected calculated parameters of the $\mathrm{BF}$ operation while injecting charcoal and biogases. Injection rate of solids (PC as reference and charcoal) was kept at $200 \mathrm{~kg} / \mathrm{tHM}$. The flame temperature was controlled by oxygen enrichment of blast. The calculations were performed for PC and charcoal presented in Table 2 and biogases presented in Tables 3 and 4.

Analysis of the results allows for a conclusion that injec- 
ISIJ International, Vol. 59 (2019), No. 12

Table 6. BF operation results (selected calculated parameters).

\begin{tabular}{|c|c|c|c|c|c|c|c|}
\hline & PC (base) & $\mathrm{CC}$ & $\mathrm{CC}+\mathrm{PG} 1$ & $\mathrm{CC}+\mathrm{PG} 1$ & $\mathrm{CC}+\mathrm{PG} 2$ & $\mathrm{CC}+\mathrm{PG} 2$ & $\mathrm{CC}+\mathrm{SG}$ \\
\hline \multicolumn{8}{|l|}{ Blast: } \\
\hline temperature, ${ }^{\circ} \mathrm{C}$ & 1200 & 1200 & 1200 & 1200 & 1200 & 1200 & 1200 \\
\hline oxygen, $\%$ & 26.78 & 25.95 & 30.12 & 35.44 & 31.23 & 40.85 & 29.36 \\
\hline $\mathrm{PC}, \mathrm{kg} / \mathrm{tHM}$ & 200 & 0 & 0 & 0 & 0 & 0 & 0 \\
\hline $\mathrm{CC}, \mathrm{kg} / \mathrm{tHM}$ & 0 & 200 & 200 & 200 & 200 & 200 & 200 \\
\hline Biogas, $\mathrm{m}^{3} / \mathrm{tHM}$ & 0 & 0 & 50 & 100 & 50 & 100 & 50 \\
\hline \multicolumn{8}{|l|}{ Calculated parameters } \\
\hline Blast volume, $\mathrm{m}^{3} / \mathrm{tHM}$ & 903 & 892 & 789 & 691 & 767 & 583 & 808 \\
\hline $\mathrm{H}_{2}$ in reduction, zone*, $\mathrm{m}^{3} / \mathrm{tHM}$ & 134 & 99 & 129 & 159 & 139 & 178 & 115 \\
\hline Coke rate, $\mathrm{kg} / \mathrm{tHM}$ & 283.1 & 265.0 & 263.8 & 264.1 & 258.3 & 240.4 & 269.5 \\
\hline Slag volume, $\mathrm{kg} / \mathrm{tHM}$ & 260 & 221 & 221 & 221 & 220 & 217 & 222 \\
\hline \multicolumn{8}{|l|}{ Top gas: } \\
\hline volume (dry), $\mathrm{m}^{3} / \mathrm{tHM}$ & 1407 & 1378 & 1310 & 1250 & 1287 & 1127 & 1336 \\
\hline $\mathrm{CO}_{2}, \%$ & 24.56 & 25.19 & 26.39 & 27.57 & 26.72 & 30.08 & 26.08 \\
\hline $\mathrm{CO}, \%$ & 23.58 & 23.41 & 26.58 & 30.13 & 26.90 & 31.31 & 26.36 \\
\hline $\mathrm{H}_{2}, \%$ & 4.67 & 3.43 & 4.90 & 6.60 & 5.39 & 7.97 & 4.29 \\
\hline $\mathrm{N}_{2}, \%$ & 47.19 & 47.97 & 42.13 & 35.70 & 41.0 & 30.64 & 43.27 \\
\hline calorific value, $\mathrm{kJ} / \mathrm{m}^{3}$ & 3486.2 & 3330.3 & 3890.8 & 4522.1 & 3983.6 & 4820.1 & 3796.0 \\
\hline temperature, ${ }^{\circ} \mathrm{C}$ & 150.3 & 152.8 & 127.5 & 104.1 & 122.4 & 86.3 & 130.2 \\
\hline \multicolumn{8}{|l|}{ Heat balance, $\mathrm{kJ} / \mathrm{kgHM}$} \\
\hline total heat generated ${ }^{* *}$ & 9791.4 & 9659.6 & 9570.4 & 9492.6 & 9547.7 & 9234.8 & 9588.5 \\
\hline useful heat absorbed ${ }^{* * *}$ & 8775.5 & 8665.7 & 8665.1 & 8665.3 & 8662.6 & 8654.5 & 8667.8 \\
\hline heat of top gas & 314.3 & 309.7 & 249.2 & 196.6 & 236.1 & 186.3 & 257.9 \\
\hline external heat loss & 701.1 & 683.1 & 655.9 & 631.6 & 648.9 & 580.3 & 662.9 \\
\hline total heat absorbed & 9790.8 & 9658.6 & 9570.3 & 9493.5 & 9547.5 & 9234.8 & 9588.5 \\
\hline Flame temperature, ${ }^{\circ} \mathrm{C}$ & 2117.0 & 2116.5 & 2116.2 & 2116.6 & 2115.1 & 2117.5 & 2116.7 \\
\hline Productivity, $\%$ & 100.0 & 102.2 & 107.5 & 112.6 & 109.4 & 124.6 & 105.5 \\
\hline $\begin{array}{l}{ }^{*} \mathrm{H}_{2} \text { entering zone of indirect reducti } \\
\text { includes combustion of } \mathrm{C} \text { of coke a } \\
\text { in reduction area }\left(\mathrm{C}-\mathrm{CO}, \mathrm{CO}-\mathrm{CO}_{2} \text {, }\right. \\
\text { *** heat for physico-chemical conver } \\
\text { and injected solid reducing agents }\end{array}$ & d injectant & in the $r$ & eway, sens & heat of & ctants and & ist, and hea & $\begin{array}{l}\text { f reactions } \\
\text {-S of coke }\end{array}$ \\
\hline
\end{tabular}

tion of biogases decreases blast volume due to rising oxygen concentration and consequently leads to higher furnace productivity. It rises by some $10-25 \%$ while injecting 100 $\mathrm{m}^{3} / \mathrm{tHM}$ biogas depending on its composition. Amount of hydrogen entering zone of indirect reduction increases by about $15-40$ and $60-80 \%$ while injecting 50 and $100 \mathrm{~m}^{3} /$ tHM of biogas respectively. It causes remarkable changes in top gas parameters: its volume and temperature decrease, hydrogen content and calorific value increase. Furthermore, heat loss decreases both external heat loss and heat of top gas. This is a further reason for the raise of furnace productivity. The optimal portion of injected biogases and charcoal depends on their compositions, BF operation conditions, as well as technological and economic goals, e.g. possibilities for oxygen enrichment of blast or demand on production rate. On the other hand, it is limited by the ratio of yields of solid and gaseous pyrolysis products, those range is shown in chapter 2. In this modelling work, three biogases were injected via tuyeres in cold state. Four further options may improve the efficiency of injection of such gases:

- Injection of hot biogases (see section 5). This proposal is based on the modelling and experimental results for injection of hot reducing gases and decarbonated top $\operatorname{gas}^{21,22)}$

- Shaft injection due to high amount of free $\mathrm{H}_{2}$ and $\mathrm{CO}$, see section 5

- Much higher injection rates, e.g. 700-1 $000 \mathrm{~m}^{3} / \mathrm{tHM}$ like in Refs. 21, 22)

- Optimisation of gas composition by decreasing the $\mathrm{CO}_{2}$ share.

\section{Optimisation of Charcoal Grain Size}

The fine grinding of injected solids is targeted at the accelerating the particle conversion due to increased specific surface area and, consequently, at improvement of the BF operation efficiency due to decrease of coke rate and energy consumption. Typically, coal fines with main mass fraction below $100 \mu \mathrm{m}$ is used for the BF injection. However, the total energy consumption should consider it demand for grinding. Thus, from economic point of view, optimisation of the material grinding instead of its minimising should 
be aimed. With this background, different size fractions of charcoals as well as a reference PC have been investigated using laboratory injection tests described in Ref. 19) combined with a microstructural analysis. Results showed that courser charcoal particles compared to coal particles can be converted under the raceway conditions, primarily due to their porous structure (Fig. 4). Furthermore, the bigger the charcoal particle, the less dependent is its conversion on $\mathrm{O} / \mathrm{C}$ ratio. It is true until a certain limit for $300-355 \mu \mathrm{m}$ and for the original poly-fractional sample (50-2 $000 \mu \mathrm{m}$, see section 2). This phenomenon might be explained by the development of charcoal microstructure.

SEM images in Fig. 5 show that the charcoal particles keep the characteristic fibrous morphology of wood and the pores are formed during the pyrolysis process. It can be recognised that the porosity increases as the particle size increases but the difference in porosity between fractions $90-125 \mu \mathrm{m}$ and $300-355 \mu \mathrm{m}$ is much higher than that between fractions $300-355 \mu \mathrm{m}$ and $630-710 \mu \mathrm{m}$. Imaging analysis of LOM pictures allowed to quantify this observation. Bigger particles possess higher porosity and larger size, Table 7. Two reasons may explain this fact. The first one is the pressure caused by the volatile matter evolved by wood decomposition, struggling the way out from the inside of the particle towards the surface after their devolatilisation/23/, pushing the solid material. The second reason is the cracking reactions, known as secondary pyrolysis, which cause the consumption of charcoal through the interaction between charcoal and the vapours. The pyrolysis vapours face a longer path in larger particles and therefore the pressure inside is higher; consequently, the size of the pores is, in average, big-

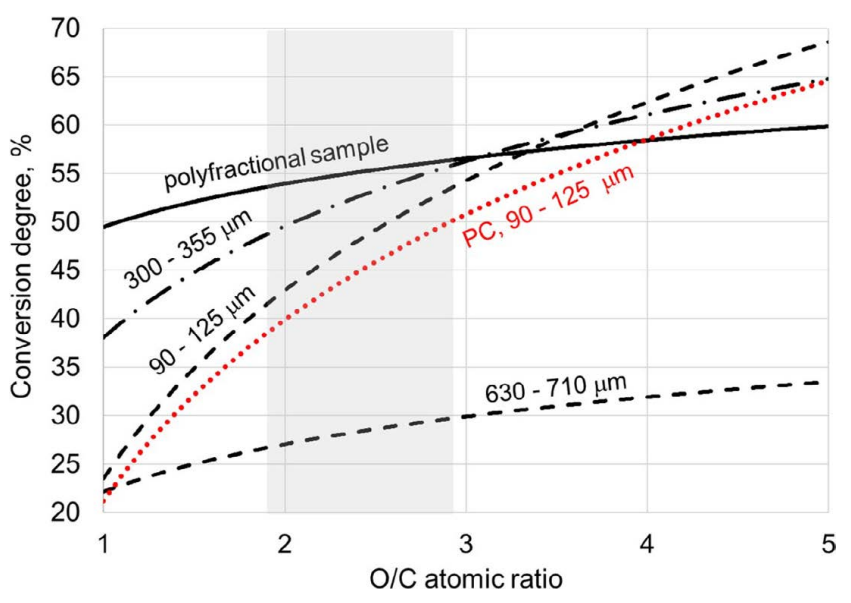

Fig. 4. Conversion behaviour of charcoals of different sizes and PC with size of $90-125 \mu \mathrm{m}$. (Online version in color.) ger. The higher porosity and pore size, the easier the oxygen to reach the surface of the particle, promoting its combustion and, therefore, the conversion degree as can be seen in Fig. 4. However, the increase in porosity is much more intense from 90-125 $\mu \mathrm{m}$ particles to $300-355 \mu \mathrm{m}$ than later on where it seems to stabilize. This explains the lower conversion degree of charcoal fraction $630-710 \mu \mathrm{m}$ : the further decreasing specific surface determines now conversion behaviour while pore characteristics are hardly changed any more.

The higher conversion degree of the original non-sieved sample in the range of $\mathrm{O} / \mathrm{C}$ atomic ratio, which corresponds to usual PC injection rate (grey area in Fig. 3), is caused primarily by wide size distribution. Co-existing fine particles ignites firstly and may influence significantly the conversion behaviour of coarser particles. This effect is valid not only for charcoals but also for PC. ${ }^{24)}$

\section{BF Control by Biomass Pyrolysis Parameters}

By the control of the blast furnace thermal state, it is beneficially to use control actions "from the bottom", i.e. by changing the amount of injected substances which are virtually free of transport delay, which makes up some $5-7 \mathrm{~h}$ for the control actions "from the top". ${ }^{11)}$ Thus, combination of synchronized changes of ore/coke ratio and amount of PC is used. ${ }^{10)}$ Furthermore, to keep constant flame temperature e.g. by changing the rates or types of injectiants, compensating measures have to be taken; thus in section 3 oxygen enrichment of blast was used. While injecting pyrolysed biomass, the efficiency and flexibility of the thermal state control can be increased by adaption of their properties. Chemistry of fossil auxiliary reducing agents such as coal, depends on their nature and is a fix value. Chemical composition and calorific value of biomass products depend on the parameters of thermal treatment (pyrolysis, torrefication) mentioned in section 2 and can be adjusted. Figure 6 shows an example of the effect of pyrolysis temperature on volatile matter and $\mathrm{C}_{\text {fix }}$ content revealed from the experiments partly presented in Ref. 25). Analysis of these and other available data leads to the conclusion that lowering the pyrolysis

Table 7. Microstructural characteristics of charcoal fractions, obtained by imaging analysis of LOM pictures at a $200 \mathrm{x}$ magnification. ${ }^{16)}$

\begin{tabular}{ccccc}
\hline Particle size $(\mu \mathrm{m})$ & & $90-125$ & $300-355$ & $630-710$ \\
\hline Porosity & $\%$ & 54.0 & 74.3 & 75.5 \\
Mean pore diameter & $\mu \mathrm{m}$ & 12.67 & 24.88 & 27.27
\end{tabular}

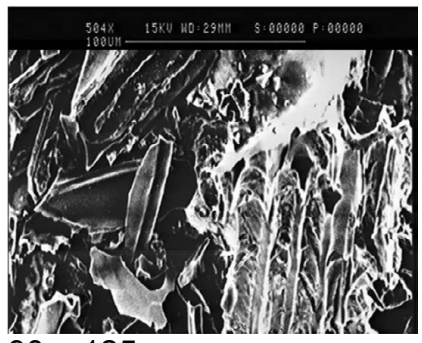

$90-125 \mu \mathrm{m}$

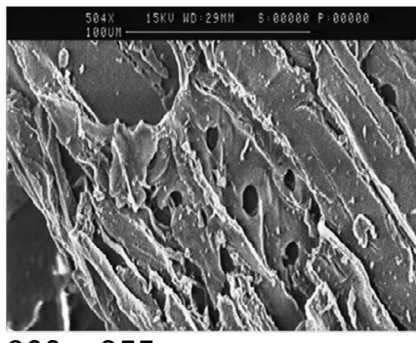

$300-355 \mu \mathrm{m}$

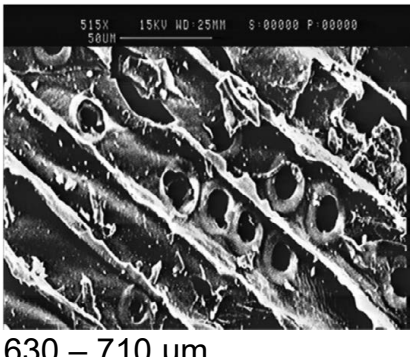

$630-710 \mu \mathrm{m}$

Fig. 5. SEM pictures of different particle size charcoal fractions at a 500x magnification. 
temperature of woody biomass by $100^{\circ} \mathrm{C}$ decreases volatile matter content typically by $9-11 \%$ and increases $\mathrm{C}_{\text {fix }}$ content by $8-10 \%$ depending on the carbonisation temperature range and time. In the case of torrefied biomass production instead of charcoals, these values are deviant and depend stronger on the biomass origin.

The control of biomass product chemistry by the pyrolysis parameters can be used to control in turn the blast furnace operation parameters, and namely, hot metal temperature and silicon content, which serve as indicators of the hearth thermal state, flame temperature and charcoal conversion degree in the raceway. This approach is shown schematically in Fig. 7.

Calculations performed using these data and the known effect of chemical composition, primarily carbon content, of carbonaceous injectants on hot metal characteristics ${ }^{26)}$ indicate that the change in hot metal temperature by $\pm 10^{\circ} \mathrm{C}$ and silicon content by $\pm 0.1 \%$ can be achieved e.g. by changing the pyrolysis temperature by $75-125^{\circ} \mathrm{C}$ in the same direction. Analogue calculations considering the volatile matters effect on flame temperature showed that change in flame temperature by $\pm 10^{\circ} \mathrm{C}$ can be achieved e.g. by changing the pyrolysis temperature by $18-22^{\circ} \mathrm{C}$ in the same direction. Similar calculations considering the known effect of $\mathrm{C}_{\mathrm{fix}}$ and VM content on conversion behaviour of carbonaceous

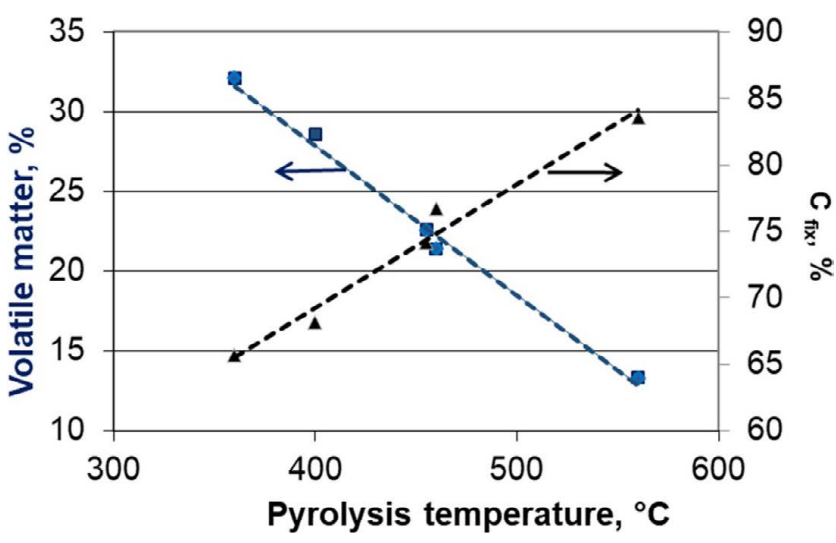

Fig. 6. Dependence of volatile matter and $\mathrm{C}_{\text {fix }}$ content on pyrolysis temperature of olive wood. (Online version in color.) injectants ${ }^{27)}$ indicate that a decrease of pyrolysis temperature by $50-100^{\circ} \mathrm{C}$ may lead to rising of the conversion degree of biomass solid products by about $10 \%$ at injection rates of $100-200 \mathrm{~kg} / \mathrm{tHM}$. These figures serve only for orientation by selecting the control actions. For the practical use at a BF plant, they must be examined for dedicated biomass and pyrolysis conditions.

Mentioned BF operation parameters can also be controlled by changing the pyrolysis time or by combination of changing pyrolysis temperature and time, as well as by changing the pyrolysis temperature profile.

The proposed BASE control method can be realised by coupling the blast furnace with a pyrolysis plant, as shown in Fig. 8. A biomass preparation plant comprises equipment for biomass feeding, pyrolysis reactor, and, optionally, a grinding and sieving equipment, although, as shown in previous section, injection of original charcoal size fractions is possible. The produced solid products, typically CC but might also be $\mathrm{TB}$, are supplied to the $\mathrm{BF}$ analogous to $\mathrm{PC}$, distributed between the tuyères and injected via lances. Hot metal temperature $\left(\mathrm{t}_{\mathrm{HM}}\right)$ and silicon content $([\mathrm{Si}])$, flame temperature $\left(\mathrm{T}_{\mathrm{f}}\right)$, as well as conversion degree of biomass products $(\eta)$ can be controlled by adjustment of pyrolysis temperature $\left(\mathrm{t}^{\circ}\right)$, heating rate $(\mathrm{dt} / \mathrm{d} \tau)$ and time $(\tau)$. Additionally, adjustment of the grinding or sieving equipment (d) can be used for the $\eta$ control. The cleaned biogas can also be used for the BF injection (blue lines in Fig. 6). It can be directly co-injected with charcoal as suggested and calculated in section 3 or it can be pre-heated before the injection. For the pre-heating, BF top gas can also be applied. Depending on the biogas composition and temperature, it can be injected via the normal hearth tuyères or/and in shaft. Similar technology was developed for top gas recycling. ${ }^{22)}$

The proposed control method can also be realised by designing the blast furnace tuyères equipped with individual pyrolysis mini-reactors. Such tuyère-reactor designs are known e.g. for coal gasification, ${ }^{28)}$ for hot reducing gas generation by partial oxidation of natural gas ${ }^{29)}$ or for oxygen sequence impulse process. ${ }^{30)}$ This variant enables individual control of charcoal conversion in each raceway zone.

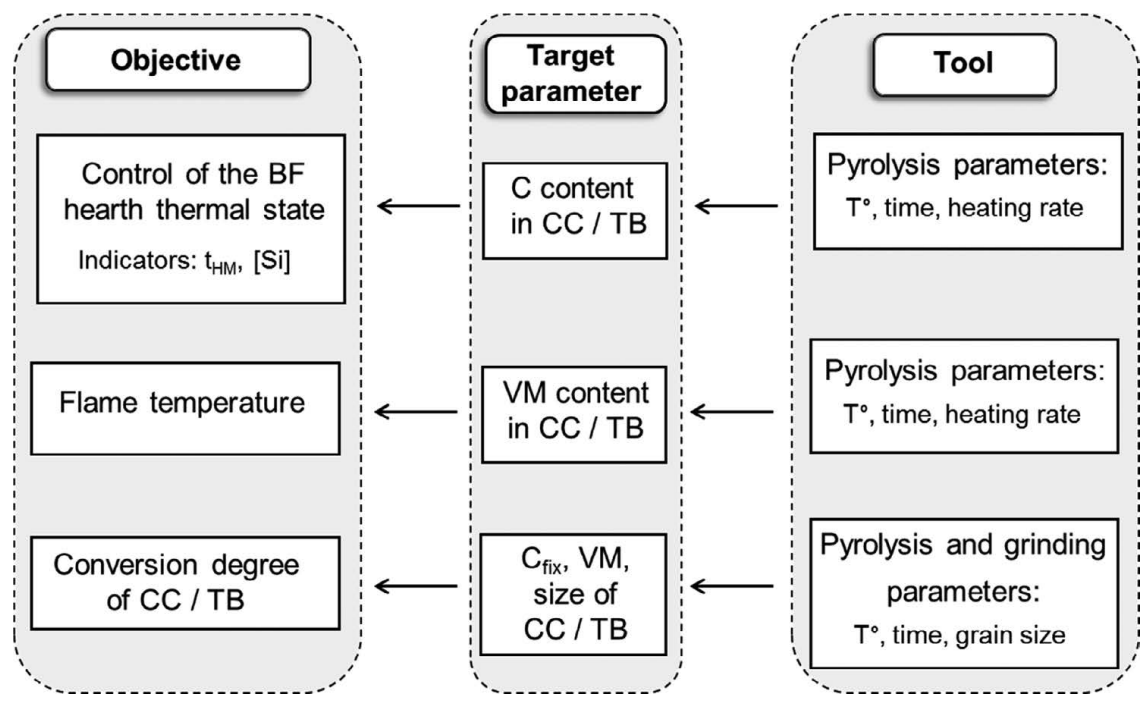

Fig. 7. Approach for the BF control by the biomass pyrolysis parameters. 


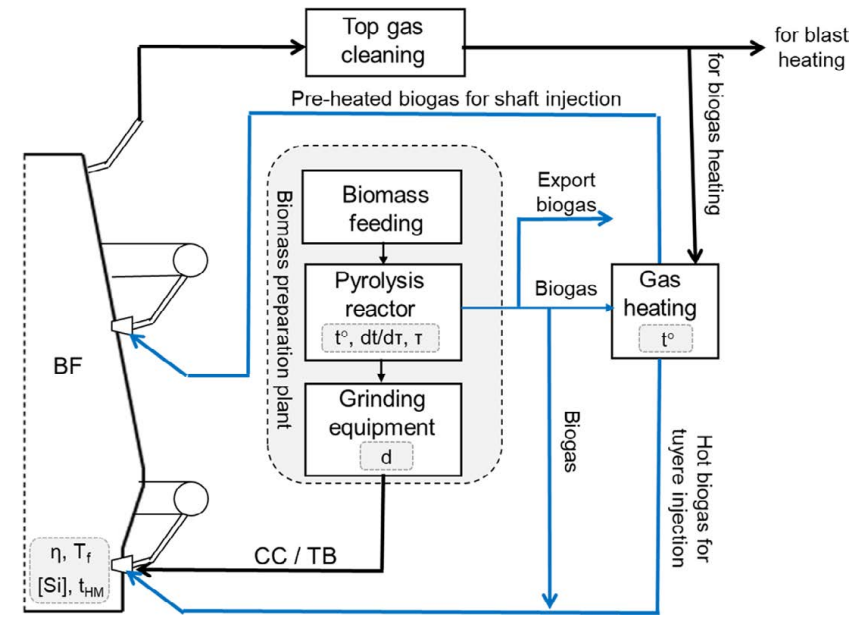

Fig. 8. Schematic representation of the proposed method for the BF thermal state control by coupling the blast furnace with a biomass pyrolysis plant. (Online version in color.)

\section{Conclusions}

Injection of $\mathrm{CC}$ and $\mathrm{TB}$ via tuyères into the $\mathrm{BF}$ was investigated in early studies. In this work, three options for raising the efficiency of biomass BF injection were suggested and examined which allow for concluding that:

(1) Share of solid, gaseous and liquid products of biomass pyrolysis in the performed experiments could be varied in the range of 20-54 wt.\% solids, 6-40 wt.\% liquids and 10-75 wt.\% gases depending on pyrolysis parameters. Composition of these products could be changed significantly as well.

(2) To resolve a dilemma that raising pyrolysis temperature and residence time enable better charcoal quality (higher fixed carbon and elemental carbon contents and lower volatile matter, elemental hydrogen and oxygen contents) but cause its lower yield, the combined use of solid and gaseous pyrolysis products by means of co-injection of charcoal and biogas was suggested. Modelling results showed that the BF productivity can be increased by $10-25 \%$ while injecting $100 \mathrm{~m}^{3} / \mathrm{tHM}$ biogas depending on its composition. Top gas volume and temperature decrease, its hydrogen content and calorific value increase. Heat loss decreases as well.

(3) A flexible method for controlling the BF thermal state based on the coupling the BF and a pyrolysis plant, and adjusting the biomass pyrolysis parameters was elaborated and examined. The control of biomass product chemistry by the pyrolysis parameters is used to control in turn the BF operation parameters, such as hot metal temperature and silicon content, flame temperature and charcoal conversion degree in the raceway. Furthermore, the cleaned biogas can be directly co-injected with charcoal or it can be pre-heated and injected in the BF hearth or/and in shaft.

(4) Coarser grinding of charcoal compared to coal would enable further energy and coast saving. It is possible due to better charcoal conversion behaviour under the raceway simulation conditions. The reasons lie primarily in its porous microstructure and raising the porosity and pore size with increasing particle size until a certain level of 300-355 $\mu \mathrm{m}$ in conducted injection tests. The higher conversion degree of the poly-fractional sample is caused by wide size distribution. Co-existing fine particles ignites firstly and increase a surrounding temperature, and thus intensify the conversion behaviour of coarser particles. This effect is valid for both charcoals and PC.

\section{Acknowledgments}

The authors wish to express thanks to Mr. F. Hippe for participating in injection tests.

\section{REFERENCES}

1) A. Babich and D. Senk: Stahl Eisen, 133 (2013), 57.

2) A. Babich, D. Senk and M. Schwarz: Proc. Innovation of Ironmaking Technologies and Future Int. Collaboration, 54th Committee on Ironmaking, Japan Society for the Promotion of Science, Tokyo, (2014), 35.

3) J. G. Mathieson, M. A. Somerville, A. Deev and S. Jahanshahi: Iron Ore, Mineralogy, Processing and Environmental Sustainability, Elsevier, Amsterdam, (2015), 581.

4) R. Wei, L. Zhang, D. Cang, J. Li, X. Li and C. C. Xu: Renew. Sustain. Energy Rev., 68 (2017), 511

5) F. Hippe, A. Babich, D. Senk, J. Solar and I. de Marco: BHM BergHüttenmänn. Monatsh., 164 (2019), 261. https://doi.org/10.1007/ s00501-019-0826-0

6) A. Babich, D. Senk and M. Fernandez: ISIJ Int., 50 (2010), 81.

7) J. Machado, E. Osório, A. Vilela, A. Babich, D. Senk and H. W. Gudenau: Steel Res. Int., 81 (2010), 9.

8) J. G. Mathieson, H. Rogers, M. Somerville, P. Ridgeway and S. Jahanshahi: Proc. METEC InSteelCon, Steel Institute VDEh, Düsseldorf, (2011), CD-ROM.

9) H. Suopajärvi and T. Fabritius: ISIJ Int., 52 (2012), 779.

10) A. Babich, D. Senk and H. W. Gudenau: Ironmaking, Stahleisen GmbH, Düsseldorf, (2016), 600.

11) A. Babich, S. Yaroshevskii, A. Formoso, A. Cores and L. Garcia: ISIJ Int., 39 (1999), 229.

12) T. Buergler, A. Ferstl, G. Pillmair, E. Schuster and A. Habermann: Proc. 27. Aachener Stahlkolloquium (27th ASK), M. Wolf GmbH, Aachen, (2012), 7 (in German).

13) A. Deev and S. Jahanshahi: Proc. 6th Int. Cong. on the Science and Technology of Ironmaking (ICSTI), Curran, Red Hook, NY, (2012), 1132.

14) M. Tripathi, J. N. Sahu and P. Ganesan: Renew. Sustain. Energy Rev., 55 (2016), 467.

15) P. Basu: Biomass Gasification, Pyrolysis and Torrefaction: Practical Design and Theory, 2nd ed., Elsevier, Amsterdam, (2013), 548.

16) J. Solar: Ph.D. thesis, School of Engineering of Bilbao, (2019), 219.

17) J. Solar, I. de Marco, B. M. Caballero, A. Lopez-Urionabarrenechea, N. Rodriguez, I. Agirre and A. Adrados: Biomass Bioenergy, 95 (2016), 416

18) M. Schwarz: Doctoral thesis, RWTH Aachen, (2019), 134

19) H. W. Gudenau, D. Senk, A. Babich, G. Böttcher, C. Froehling, O. S. Kweon, S. Wang and T. Wieting: ISIJ Int., 44 (2004), 1469.

20) F. Hanrot, D. Sert, A. Babich, R. Pietruck, M. Fernandez, M. A. Diez, T. Bürgler and J. Delinchant-Lété: Short term $\mathrm{CO}_{2}$ mitigation for steelmaking (SHOCOM), European Commission, Luxembourg, (2011), 108. 10.2777/8592

21) A. Babich, H. W. Gudenau, K. Mavrommatis, C. Fröhling, A. Formoso, A. Cores and L. Garcia: Rev. Metal., 38 (2002), 288.

22) J. van der Stel, M. Hattink, C. Zeilstra, G. Louwerse, A. Hirsch, U. Janhsen, D. Sert, M. Grant, A. Delebecque, P. Diez-Brea, J. Adam, O. Ansseau, A. Feiterna, R. Lin, A. M. Zagaria, W. Küttner, R. Schott, N. Eklund, M. Pettersson, A. Boden, B.-E. Sköld, L. Sundqvist, J.-P. Simoes, N. Edberg, J. Lövgren, T. Bürgler, C. Feilmayr, M. Sihvonen, O. Kerkkonen, A. Babich and S. Born: ULCOS top gas recycling blast furnace process (ULCOS TGRBF), European Commission, Luxembourg, (2014), 47. https://doi.org/10.2777/59481

23) P. Basu: Introduction in Biomass Gasification Pyrolysis: Practical Design and Theory, 1st ed., Elsevier, Oxford, (2010), 376.

24) V. N. Andronov, A. I. Babich, S. L. Yaroshevskii, A. I. Ivanov, I. A. Pakhomov, O. K. Anufriev and Y. Nai-fu: Steel USSR - Engl. Transl., 18 (1988), 197.

25) A. Babich, D. Senk and M. Fernandez: Proc. 5th Int. Cong. on the Science and Technology of Ironmaking (ICSTI'09), CSM, Shanghai, (2009), 762

26) A. I. Babich, S. L. Yaroshevskii, O. V. Mitasov, E. N. Skladanovskii, G. E. Nekhaev and V. V. Stepanov: Steel USSR - Engl. Transl., 12 (1982), 189.

27) H. T. Ho, A. Babich, D. Senk and J. Frank: Proc. 7th European Coke and Ironmaking Cong. (ECIC 2016), ASMET, Linz, (2016), 845.

28) I. G. Tovarovskii, A. P. Pukhov, V. S. Shvedov, Yu. A. Dronov, E. G. Shadek, A. A. Tretyak, E. N. Tikhomirov, A. A. Kasatkin, I. I. Solodkii and G. I. Tovarovskaya: Steel Transl., 27 (1997), 1.

29) J. Buchwalder, J. Mernitz, G. Harp, M. Hensmann, C. Reuther and M. Schingnitz: Proc. METEC InSteelCON 2007, Steel Institute VDEh, Düsseldorf, (2007), 298.

30) R. Klock, M. Peters, H.-H. Heldt, G. König and W. Langkabel: MPT Int., (2019), February, 24. 